\title{
COMPARISON OF EFFECT OF FENTANYL AND DEXMEDETOMIDINE ON POST-OPERATIVE ANALGESIA AND HAEMODYNAMICS WHEN ADDED TO BUPIVACAINE 0.5\% IN EPIDURAL BLOCK FOR PELVIC AND LOWER LIMB ORTHOPAEDIC SURGERIES
}

\author{
Vivek Chakole1, Krishna Pandey², Deepak Joshi ${ }^{3}$
}

${ }_{1}^{1}$ Associate Professor, Department of Anaesthesiology, CMM Memorial Medical College, Kachandur, Durg, Chhattisgarh.

${ }^{2}$ Senior Resident, Department of Anaesthesiology, Govind Vallabh Pant Institute of Post-Graduate Medical Education and Research,

New Delhi.

${ }^{3}$ Professor, Department of Anaesthesiology, R. D. Gardi Medical College, Ujjain, Madhya Pradesh.

\begin{tabular}{l}
\hline ABSTRACT \\
\hline BACKGROUND \\
This study was designed to investigate whether the addition of fentanyl or dexmedetomidine to bupivacaine for epidural block \\
would prolong postoperative pain relief and reduce the need for additional analgesics block in pelvic and lower limb orthopaedic \\
surgeries.
\end{tabular}

\section{OBJECTIVE}

Comparison of effect of $1.0 \mathrm{mcg} / \mathrm{kg}$ of Dexmedetomidine and Fentanyl $2 \mathrm{mcg} / \mathrm{kg}$ on post-operative analgesia and haemodynamic when added to bupivacaine $0.5 \%$ in epidural block for pelvic and lower limb orthopaedic surgeries.

\section{MATERIAL AND METHOD}

In our randomized control trial, total 75 adult ASA class I and II patients undergoing lower limb orthopaedic and pelvic surgeries were given epidural block and studied for addition of dexmedetomidine and fentanyl on intraoperative haemodynamic and post-operative analgesia. Patients received $0.5 \%$ bupivacaine $20 \mathrm{~mL}$ in one group and we added Dexmedetomidine $1.0 \mathrm{mcg} / \mathrm{kg}$ and Fentanyl $2 \mathrm{mcg} / \mathrm{kg}$ in the other 2 groups respectively. All the patients were monitored for onset of effect, intraoperative haemodynamic, post-operative analgesia and complications.

\section{RESULT}

The mean time for onset of sensory block was significantly rapid in dexmedetomidine and fentanyl group as compared to bupivacaine group. The offset time of sensory and motor block was prolonged in dexmedetomidine group in comparison to control and fentanyl group. Addition of Dexmedetomidine substantially prolongs postoperative pain free period than Fentanyl and Bupivacaine.

\section{CONCLUSION}

Addition of Dexmedetomidine, an alpha-2 agonist to local anaesthetic solution for conduct of lumbar epidural block in the dose range of $1.0 \mathrm{mcg} / \mathrm{kg}$ substantially prolongs postoperative pain free period without altering block characteristics offered by Bupivacaine and is a better adjuvant than fentanyl, an opioid, but it also prolongs the motor blockade which may hamper early mobilization of patients.

\section{KEYWORDS}

Epidural Anaesthesia, Bupivacaine, Dexmedetomidine, Fentanyl.

HOW TO CITE THIS ARTICLE: Chakole V, Pandey K, Joshi D. Comparison of effect of fentanyl and dexmedetomidine on postoperative analgesia and haemodynamics when added to bupivacaine $0.5 \%$ in epidural block for pelvic and lower limb orthopaedic surgeries. J. Evolution Med. Dent. Sci. 2016;5(57):3903-3907, DOI: 10.14260/jemds/2016/894

\section{INTRODUCTION}

Regional anaesthesia is supposed to be excellent anaesthesia in terms of safety and prolong post-operative pain relief. In modern regional anaesthesia, epidural blockade is one of the best procedures providing better intraoperative haemodynamic control, post-operative pain relief and rapid recovery from surgery, specially pelvic surgeries and orthopaedic surgeries.

Financial or Other, Competing Interest: None.

Submission 03-05-2016, Peer Review 02-06-2016,

Acceptance 07-06-2016, Published 15-07-2016.

Corresponding Author:

Dr. Vivek Chakole,

Associate Professor,

Department of Anaesthesiology,

C.M.M. Memorial Medical College,

Kachandur, Durg, Chhattisgarh.

E-mail: drvivekchakole@rediffmail.com

DOI: $10.14260 /$ jemds $/ 2016 / 894$
Bupivacaine is long-acting amide local anaesthetic, which is in use since 1957. It is commercially available as racemic mixture containing equal proportion of the S (-) and $\mathrm{R}(+)$ isomers.

Many adjuvants have been used with bupivacaine to increase the post-operative analgesia. Earliest agent was epinephrine. Epidural neostigmine was used and have high incidence of nausea vomiting. Epidural opioids like morphine, pethidine, buprenorphine and fentanyl giving excellent postoperative analgesia, but associated with side effects like respiratory depression, pruritus, sedation, nausea and vomiting.

Selective alpha-2 adrenergic agonist were used as adjuvants in epidural blockade. Clonidine hydrochloride was the first drug from the group and was found clinically useful in peri-operative period. ${ }^{1}$

Dexmedetomidine, a more powerful and highly selective alpha-2 adrenoceptor agonist than clonidine and was 
introduced in clinical practice in 1999 and soon became popular for variety of indications in Anaesthesiology.2,3,4

Various studies conducted that the addition of Dexmedetomidine or fentanyl to bupivacaine in epidural block offers acceptable level sedation and post-operative analgesia. It is important to compare post-operative analgesia and side effects of both drugs when administered by epidural route. $4,5,6,7$

The current prospective randomized double-blind study was undertaken in orthopaedic and pelvic surgical patients to evaluate the effectiveness of fentanyl and dexmedetomidine, acting by two different mechanisms administered by lumbar epidural route with $0.5 \%$ bupivacaine and complications associated with their use.

\section{MATERIAL AND METHOD}

A randomized study comparison of the effect of addition of fentanyl and dexmedetomidine on post-operative analgesia when added to bupivacaine $0.5 \%$ in epidural block was carried out in 75 patients undergoing lower limb orthopaedic and pelvic surgeries.

Appropriate approval was taken from Hospital Ethics Committee. All patients selected were planned for surgeries, of ASA Grade I or II, aged 15-65 years, weighing 40-70 Kg. Patients with haematological diseases, abnormal bleeding and clotting time, psychiatric disease, diabetes, sepsis at the site of injection, spinal deformities, non-consenting patients and patient with allergy to local anaesthetic agent were excluded from the study. After detailed examination and informed consent, patients were randomly assigned in 3 groups of 25 patients each.

In the operation theatre, a good intravenous access was secured and monitoring devices were attached recording baseline heart rate, Electrocardiogram (ECG), pulse oximetry $\left(\mathrm{SpO}_{2}\right)$, Non-Invasive Blood Pressure (NIBP), respiratory rate. The drug syringes were prepared with all aseptic technique. After antiseptic preparation of back and covering the part with sterile drape, the selected space for epidural puncture was infiltrated with $1 \mathrm{~mL}$ of $2 \%$ Xylocaine solution, epidural puncture was done in the midline by using 18-gauge Tuohy (Romsons) needles in sitting position and epidural space was identified by the loss of resistance to air injection technique. Procedure was conducted by same anaesthesiologist every time.

After identifying the space, a test dose of $2 \mathrm{~mL}$ lignocaine hydrochloride solution containing adrenaline 1:200000 was injected to avoid accidental intravascular injection or massive intrathecal dose. After 2-3 minute of administering the test dose, Group C patients received local anaesthetic solution $0.5 \%$ preservative free Bupivacaine $20 \mathrm{~mL}$ with $2 \mathrm{~mL}$ water for injection as a single dose injection.
Group D received local anaesthetic solution, $0.5 \%$ preservative free Bupivacaine $20 \mathrm{~mL}$ with $1.0 \mathrm{mcg} / \mathrm{kg}$ of Dexmedetomidine with $2 \mathrm{~mL}$ water for injection was injected as a single dose injection.

Group F received local anaesthetic solution, $0.5 \%$ preservative free Bupivacaine $20 \mathrm{~mL}$ with $2 \mathrm{mcg} / \mathrm{kg}$ of fentanyl ( $2 \mathrm{~mL}$ ) was injected as a single dose injection.

After injection of drug (As per the group assigned), patient was made to lie down supine with 10-degree head low tilt and each patient was observed for:

A. Time of onset for sensory block.

B. Time of onset of motor block.

C. Highest level of sensory block achieved (by pinprick method).

D. Duration of sensory block.

E. Duration of motor block.

F. Intraoperative muscle relaxation (On Bromage scale).

G. Degree of sedation on Ramsay sedation scale.

H. Duration of pain free period.

I. Any adverse drug effect.

J. Any complication like bradycardia, hypotension, respiratory depression, nausea, vomiting, itching, urinary retention and shivering.

An independent observer who was totally unaware of the nature of the study, recorded blood pressure and heart rate just before and after surgical incision and then every five minutes interval till the end of surgery using multiparameters.

Postoperatively, patient was monitored for offset time of epidural block (Motor and sensory regression).

\section{RESULTS}

\begin{tabular}{|c|c|c|c|}
\hline Group & Group C & Group D & Group F \\
\hline Age in years & $48.68 \pm 10.18$ & $42.72 \pm 11.17$ & $44.76 \pm 11.8$ \\
\hline Sex male & 14 & 12 & 12 \\
\hline Female & 11 & 13 & 13 \\
\hline Weight in kg & $52.6 \pm 7.26$ & $54.4 \pm 6.83$ & $54.04 \pm 6.94$ \\
\hline Height in cm & $165.5 \pm 6.42$ & $165.8 \pm 7.5$ & $165.5 \pm 6.46$ \\
\hline \multicolumn{4}{|c|}{ Table 1: Demographic Data } \\
\hline
\end{tabular}

Demographic data of patient included in the study was comparable with respect to height, weight and mean age of patient in each group.

Patients included in the study had a mean age of 45.38 years (20-60 years). Male/female ratio was 38/37. The patients included in the study were adults and had vital signs within normal limits with no comorbid condition and thus belonged to grade I/II as per ASA classification.

\begin{tabular}{|c|c|c|c|}
\hline Group & Group C & Group D & Group F \\
\hline Mean time onset of sensory block (seconds) & $679.2 \pm 86.11$ & $627.6 \pm 58.04$ & $628.8 \pm 65.08$ \\
\hline Mean time onset of motor block seconds & $1003.2 \pm 130.21$ & $890.4 \pm 126.9$ & $955.2 \pm 140.62$ \\
\hline Duration of sensory block (Minutes) & $255.2 \pm 25.55$ & $286.8 \pm 12.85$ & $243.8 \pm 12.85$ \\
\hline Duration of motor block (Minutes) & $205 \pm 25.5$ & $252.8 \pm 38.02$ & $213.6 \pm 13.58$ \\
\hline Post-operative analgesia hrs. & $4.83 \pm 0.58$ & $10.52 \pm 1.71$ & $5.15 \pm 0.57$ \\
\hline Hypotension & $3(12 \%)$ & $5(20 \%)$ & $3(12 \%)$ \\
\hline Bradycardia & - & $3(12 \%)$ & - \\
\hline Shivering & $2(8 \%)$ & - & $1(4 \%)$ \\
\hline Nausea & $3(12 \%)$ & - & - \\
\hline Vomiting & $2(8 \%)$ & - \\
\hline
\end{tabular}


The mean time for onset of sensory block was significantly rapid in group D (627.6 seconds) and group $\mathrm{F}$ (628.8 seconds) as compared to group C (679.2 seconds), but the difference was not statistically significant between Group D and Group F.

The mean time for onset of motor block was significantly rapid in group D (890.4 seconds) and group F (955.2 seconds) as compared to group C (1003.2 seconds), but the difference was not significant between Group D and Group F.

The mean offset time for sensory block (Regain of sensitivity to pinprick at S1 dermatome) in control group was found to be $255.2 \pm 25.55$ minutes, whereas group D $286.8 \pm 35.79$ minutes and group F $243.8 \pm 12.85$ minutes. The mean offset time for sensory block was longest in group D. There was statistically highly significant difference between group C and D, and between group C and group F. Offset time difference was not statistically significant between group D and group F.

The mean offset time for motor block (Tested by Bromage scale - regain of ability to cause flexion at ankle) in control group was found to be $205.2 \pm 25.5$ minutes, whereas group D $252.8 \pm 38.02$ minutes and group F $213.6 \pm 13.58$ minutes. The mean offset time of motor block was longest in group D. Statistically, highly significant difference was seen in group $C$ and D, also between group D and group F. Difference between group $\mathrm{C}$ and $\mathrm{F}$ was not statistically significant.

Highest time for pain free period was recorded in group D patients and it was found to be $10.52 \pm 1.71$ hours, which was followed by group $F$ patients who had pain relief for $5.15 \pm 0.57$ hours. In control group, patient's shortest pain free period was seen and it was $4.83 \pm 0.58$ hours. The duration of analgesia was longest in dexmedetomidine group and the mean value was statistically highly significant as compared to fentanyl and control group. Time of post-operative pain free period between group $\mathrm{C}$ and group $\mathrm{F}$ was not statistically significant.

Incidence of shivering, nausea is more in control group than fentanyl group; none of it in dexmedetomidine group. Vomiting was seen in $8 \%$ of patients in control group, but not in dexmedetomidine and fentanyl groups.

\begin{tabular}{|c|c|c|c|}
\hline $\begin{array}{c}\text { Dermatome } \\
\text { Height }\end{array}$ & $\begin{array}{c}\text { Group C } \\
(\mathbf{n = 2 5})\end{array}$ & $\begin{array}{c}\text { Group D } \\
(\mathbf{n = 2 5})\end{array}$ & $\begin{array}{c}\text { Group F } \\
(\mathbf{n = 2 5 )}\end{array}$ \\
\hline T6 & $9(36 \%)$ & $17(68 \%)$ & $19(76 \%)$ \\
\hline T8 & $13(52 \%)$ & $7(28 \%)$ & $5(20 \%)$ \\
\hline T10 & $3(12 \%)$ & $1(4 \%)$ & $1(4 \%)$ \\
\hline \multicolumn{4}{|c|}{ Table 3: Highest Sensory Level Achieved } \\
\hline
\end{tabular}

Highest Level of block achieved in these patients was up to T6 dermatome in $36 \%$ in control group, $68 \%$ in group D and $76 \%$ in group F. Sensory block up to T6 level was more in dexmedetomidine and fentanyl group than control group, but no difference between dexmedetomidine and fentanyl group.

\begin{tabular}{|c|c|c|c|}
\hline $\begin{array}{c}\text { Sedation } \\
\text { Score }\end{array}$ & $\begin{array}{c}\text { Group A } \\
(\mathbf{n = 2 5 )}\end{array}$ & $\begin{array}{c}\text { Group D } \\
(\mathbf{n = 2 5})\end{array}$ & $\begin{array}{c}\text { Group F } \\
(\mathbf{n = 2 5 )}\end{array}$ \\
\hline 1 & 0 & 0 & 0 \\
\hline 2 & 7 & $1(04 \%)$ & $6(24 \%)$ \\
\hline 3 & $18(72 \%)$ & $15(60 \%)$ & $19(76 \%)$ \\
\hline 4 & 0 & $7(28 \%)$ & 0 \\
\hline 5 & 0 & 0 & 0 \\
\hline 6 & 0 & 0 & 0 \\
\hline \multicolumn{4}{|c}{ Table 4: Sedation Score } \\
\hline
\end{tabular}

For assessment of sedation, 6 points non-parametric scale designed by Ramsay was employed in this study. No patients from study or control group receive tranquilizer or narcotic analgesics. Sedation score of 4 was seen in $28 \%$ patients of group D: score was 3 in 18 patients of group C, 15 patients of group D and 19 patients in group F. Score was 2 in 7 patients of group C, 1 in group D and 6 in group F. No patient from any group had score 1,5 and 6 .

\begin{tabular}{|c|c|c|c|}
\hline $\begin{array}{c}\text { Muscle Power } \\
\text { Grading }\end{array}$ & $\begin{array}{c}\text { Group C } \\
(\mathbf{n = 2 5})\end{array}$ & $\begin{array}{c}\text { Group D } \\
(\mathbf{n = 2 5})\end{array}$ & $\begin{array}{c}\text { Group F } \\
(\mathbf{n = 2 5})\end{array}$ \\
\hline 1 & 0 & 0 & 0 \\
\hline 2 & $12(48 \%)$ & $8(32 \%)$ & $9(36 \%)$ \\
\hline 3 & $13(52 \%)$ & $17(68 \%)$ & $16(64 \%)$ \\
\hline \multicolumn{4}{|c|}{ Table 5: Degree of Muscle Relaxation } \\
\hline
\end{tabular}

In majority of the patients, degree of muscle relaxation in study and control group was acceptable and provide smooth intraoperative period. Muscle power grade 3 was seen in $68 \%$ patients in group D, $64 \%$ in patients in group $\mathrm{F}$ and $52 \%$ in group $\mathrm{C}$. The degree of muscle relaxation can be attributed to bupivacaine and not to drugs used as an adjuvant.

\begin{tabular}{|c|c|c|c|c|}
\hline Groups & $\begin{array}{c}\text { Preoperative } \\
\text { HR/bpm }\end{array}$ & $\begin{array}{c}\text { Minimum } \\
\text { HR/bpm }\end{array}$ & Changes & Bradycardia \\
\hline $\begin{array}{c}\text { Group C } \\
(\mathrm{n}=25)\end{array}$ & $89.28 \pm 12.12$ & $64.36 \pm 8.76$ & $27.91 \%$ & 0 \\
\hline $\begin{array}{c}\text { Group D } \\
(\mathrm{n}=25)\end{array}$ & $87.36 \pm 12.08$ & $61.52 \pm 8.54$ & $29.57 \%$ & $3(12 \%)$ \\
\hline $\begin{array}{c}\text { Group F } \\
(\mathrm{n}=25)\end{array}$ & $85.56 \pm 11.38$ & $64 \pm 8.01$ & $21.56 \%$ & 0 \\
\hline \multicolumn{5}{|c|}{ Table 6: Changes in Heart Rate } \\
\hline
\end{tabular}

In each group, pre-operative mean heart rate and respiratory rate was tabulated and subjected to calculations. Pre-operative mean heart rate in control group was 89.28 bpm and in group D and group F it was 87.36 and 85.56 bpm respectively. Maximum lowering of mean heart rate by $29.57 \%$ was seen in group D patients. In group C and group $\mathrm{F}$, fall in mean heart rate was $27.91 \%$ and $21.56 \%$ respectively. There was incidence of bradycardia in group D in $12 \%$ patients, but not in group $\mathrm{C}$ and group $\mathrm{F}$. Bradycardia was treated with injection Atropine $0.6 \mathrm{mg}$ IV.

\begin{tabular}{|c|c|c|c|c|}
\hline Groups & $\begin{array}{c}\text { Pre-Block } \\
\text { MAP } \\
(\mathbf{m m H g})\end{array}$ & $\begin{array}{c}\text { MAP } \\
\text { Minimum } \\
(\mathbf{m m H g})\end{array}$ & $\begin{array}{c}\text { Changes } \\
(\%)\end{array}$ & Hypotension \\
\hline $\begin{array}{c}\text { Group } \\
\text { C } \\
(\mathrm{n}=25)\end{array}$ & $95.84 \pm 7.72$ & $77.32 \pm 6.99$ & 19.32 & $3(12 \%)$ \\
\hline $\begin{array}{c}\text { Group } \\
\text { D } \\
(\mathrm{n}=25)\end{array}$ & $95.96 \pm 7.62$ & $76.84 \pm 7.66$ & 19.92 & $5(20 \%)$ \\
\hline $\begin{array}{c}\text { Group } \\
\mathrm{F} \\
(\mathrm{n}=25)\end{array}$ & $93.32 \pm 8.5$ & $75.28 \pm 6.64$ & 18.04 & $3(12 \%)$ \\
\hline \multicolumn{5}{|c|}{ Table 7: Changes in Mean Arterial Pressures } \\
\hline
\end{tabular}

Changes from preoperative mean of MAP to post block period was similar in all groups and was $19.32 \%, 19.92 \%$ and $19.33 \%$ in group $\mathrm{C}, \mathrm{D}$ and $\mathrm{F}$ respectively. Incidence of hypotension (MAP $<70 \mathrm{mmHg}$ or decrease of more than 20\%) was more in group D (20\%) than group C (12\%) and group D (12\%) and hypotension well responded to mephentermine 3$6 \mathrm{mg}$ IV and bolus IV crystalloids. 


\section{DISCUSSION}

It is well-established that Bupivacaine offer good anaesthesia in Epidural Block. However, anaesthesiologists persistently attempted to improve the quality of block by adding adjuvant drugs to local anaesthetics. Adjuvants enhance the effectiveness and qualities of analgesia offered by local anaesthetics alone and also prolongs the post-operative pain free period and decrease the requirement of systemic analgesics with minimum and no side effects and least possible effect on haemodynamic.

Central neuraxial administration of opioids began after demonstration of opioids receptors in substantia gelatinosa in spinal cord of animal by Paul Bert Sydner (1973) and Wang (1979). Yaksh and Ruddy (1985) demonstrated the safety of morphine and analogue in human volunteer. ${ }^{8}$

Several publications have declared that the addition of morphine and its analogue, fentanyl citrate in present study, to local anaesthetic solution increases the duration of sensory and motor block and increases the post-operative pain free period by their action on opioid receptors and thereby reducing the postoperative consumption of analgesic. Central neuraxial administration of opioids is associated with clinically acceptable incidence of manageable side effects like pruritus, tingling, delayed respiratory depression, urinary retention, etc. Chen Hwan CherngChih Shun Wong and Shung Tai HO (2001), Habab F Khafagy et al (2010), Barbra A Coda et al (1994) and many more have reported the characters of spinal and epidural block after addition of Fentanyl citrate to local anaesthetic solution. They found that fentanyl speeds the onset of sensory block, prolongs sensory and motor block and post-operative pain free period enhancement and dose dependent incidences of side effects. ${ }^{9}$

Role and presence of alpha-2 adrenoceptors in pain modulation were defined by Yaksh (1985) and evidences of induction of analgesia by clonidine, in spinal administration in small animals and human volunteers began their use as adjuvants to local anaesthetics. ${ }^{10}$

Dexmedetomidine is another alpha-2 adrenoceptor agonist and has been introduced for clinical use in our country recently. ${ }^{11}$ Numerous clinical studies have clearly established role of fentanyl as an adjuvant to bupivacaine and the effectiveness of fentanyl significantly prolongs postoperative pain free period. There for the discussion below, we compared our results with those studies in which dexmedetomidine were administered with bupivacaine or other local anaesthetic by epidural route.

Arakawa M., Hoka S. (1998) looked for optimal dose of fentanyl via epidural route and found $3 \mathrm{mcg} / \mathrm{kg}$ as optimum does. ${ }^{12}$ In present study, we used $2 \mathrm{mcg} / \mathrm{kg}$. Bajwa SJ (2011) used $1 \mathrm{mcg} / \mathrm{kg}$ dexmedetomidine by epidural route, we employed same dose in present study. ${ }^{13,14}$

The demographic data like age, sex and weight are comparable among control and study groups.

The mean onset time of sensory block was 679.2 seconds in group C, 627.6 seconds in group D and 628.8 seconds in group $\mathrm{F}$. The mean onset time of motor block was 890.4 seconds in group D, 955.2 seconds in group F and 1003.2 seconds in group $\mathrm{C}$.

The mean onset time of both sensory and motor block was significantly rapid in group D in comparison to group C.
The difference was not significant between group D and F in the onset of sensory and motor block. It was not significant on onset of motor block between group $\mathrm{C}$ and $\mathrm{F}$.

Bajwa et al 2011 reported early onset of sensory and motor block with dexmedetomidine in lumbar epidural block where fentanyl and dexmedetomidine were added to ropivacaine.13,14 Rajni Gupta 2011.4 Al-Ghanem SM 2009.10 used dexmedetomidine and fentanyl as an adjuvant in subarachnoid block with Bupivacaine. No significant difference was seen on the onset of sensory and motor block with fentanyl and dexmedetomidine.

The offset time of sensory and motor block was prolonged in dexmedetomidine group in comparison to control and fentanyl group and the difference was highly significant, but not significant for dexmedetomidine and fentanyl group. Bajwa et al also reported similar findings and found that dexmedetomidine as in adjuvant in epidural block is superior to fentanyl in terms of offset of sensory and motor block.13,14

Bajwa et al 2011 reported the first rescue dose was significantly prolonged in patients where dexmedetomidine was used as an adjuvant to ropivacaine in epidural block as compared to fentanyl. ${ }^{13,14}$ Rajni Gupta et al reported time to rescue analgesia was prolonged in dexmedetomidine group as compared to fentanyl group; however, drug was given intrathecally as an adjuvant to bupivacaine. 5 In our study, same results obtained with highest post-operative pain free time $10.52 \mathrm{hrs}$. in dexmedetomidine group which was significantly prolonged than fentanyl ( $5.15 \mathrm{hrs}$.) and control group (4.83 hrs.).

Sedation score of 4 was seen in $28 \%$ patients of group D indicating that dexmedetomidine alpha-2 agonist has produced good sedation along with sensory and motor block. In none of the patients of group $\mathrm{C}$ and $\mathrm{F}$ sedation score of 4 was observed. In the present study, Ramsay sedation score was used. Bajwa et al 2011 compared the sedation score in a similar study and found that level of sedation was more in dexmedetomidine as compared to fentanyl group on subjective sedation scale. It indicates that sedation is superior with alpha-2 agonist compared to opioid. ${ }^{13,14}$

The relief from anxiety, sedation and sympatholysis are due effects of dexmedetomidine on pre- and post-synaptic sympathetic nerve terminal and central nervous system, which is not seen in cases of fentanyl treated patients.

There was adequate muscle relaxation. Muscle power grade 3 was seen in $68 \%$ patients in group D and $64 \%$ patients in group $\mathrm{F}$ and $52 \%$ in group $\mathrm{C}$. The degree of relaxation can be attributed to bupivacaine and not to drugs used as an adjuvant. Bajwa et al 2011 reported similar observations. ${ }^{13,14}$

In present study heart rate, mean arterial pressure, respiratory rate and $\mathrm{Sp} 02$ were observed up to three hours after block. There was no difference in the changes produced in all the three groups. The heart rate was decreased by $27.91 \%$ I group C, $29.57 \%$ in group D and $25.19 \%$ in group $\mathrm{F}$. In 3 cases of group D, there was decrease in heart rate by less than $50 \mathrm{bpm}$ and was adequately treated by injection Atropine $0.6 \mathrm{mg}$ IV.

The mean of maximum reduction in mean arterial pressure post block was similar in all three groups and was from $19.32 \%$ to $19.91 \%$. In 5 cases of dexmedetomidine group, 3 cases of group control and fentanyl there was hypotension and was treated with injection mephentermine 
and crystalloid intravenously. Similar observations were made by Bajwa et al 2011. The changes in heart rate and MAP have been attributed to sympathetic blockade due to alpha-2 agonist and clinically manageable. ${ }^{13,14}$

Opioids are associated with respiratory depression, but in present study there was not even one case of respiratory depression and can be explained on the basis that fentanyl is less likely to induce respiratory depression as compared to morphine. Respiratory depression is not a feature of alpha-2 agonist. Bajwa et al 2011 reported that the reasonable degree of haemodynamic stability is provided on adding dexmedetomidine and fentanyl to epidural ropivacaine. ${ }^{13,14}$

Shivering was seen in 2 cases of group $C$ and 1 case of group F. Nausea was seen in 3 cases of group $C$ and 1 case of group F; and Vomiting was seen in 2 cases of group C. The opioid administration is known to produce itching, nausea, and vomiting, respiratory depression and urine retention.

In one study by Michael Smith and Marrof. ${ }^{15}$ used Dexmedetomidine successfully to prevent shivering associated with anaesthesia.

The incidence of side effects was least in group D and was related to haemodynamic seen as bradycardia and hypotension which were managed with ease.

Motor and sensory block prolonged in dexmedetomidine group as compared to Control and Fentanyl Group.

Dexmedetomidine group showed clinically and statistically highly significant in post-operative pain free period in comparison to control and fentanyl group.

\section{CONCLUSION}

Addition of Dexmedetomidine, an alpha-2 agonist to local anaesthetic solution for conduct of lumbar epidural block in the dose range of $1.0 \mathrm{mcg} / \mathrm{kg}$ substantially prolongs postoperative pain free period without altering block characteristics offered by Bupivacaine and is a better adjuvant than fentanyl, an opioid, but it also prolongs the motor blockade which may hamper early mobilization of patients.

\section{REFERENCES}

1. Kamibayashi T, Maze M. Clinical uses of alpha-2 adrenergic agonists. Anaesthesiology 2000;93(5): 1345-9.

2. Rawal N, Sjostrand UH. Clinical application of epidural and intrathecal opioids for pain management. International Anaesthesiology clinics 1986:24(2):43-57.
3. Bogre J, Gupta R, Verma R, et al. Dexmedetomidine as an intrathecal adjuvant for postoperative analgesia. Indian J Anaesth 2011;55(4):347-51.

4. Wolfe MJ, Davis GK. Analgesic action of extradural fentanyl. Br J Anaesth 1980:52(3):357-8.

5. Bloor BC, Ward DS, Belleville JP, et al. Effects of intravenous dexmedetomidine in humans II hemodynamic changes. Anaesthesiology 1992;77(6): 1134-42.

6. Adanir KS, Yilmaz T, Rezanko G, et al. The efficacy and neurotoxicity of dexmedetomidine administered via the epidural route. European Journal of Anaesthesiology 2008;25(5):403-9. Doi:10.1017/S0265021507003079.

7. Anand VG, Kannan M, Thavamani A, et al. Effect of dexmedetomidine added to caudal ropivacaine in paediatric lower abdominal surgeries. Indian J Anaesth 2011;55(4):340-6.

8. Snyder SH. Opiate receptors in the brain. The New England J Medicine 1977;296:266-71.

9. Cherng $\mathrm{CH}$, Wong CS, Ho ST. Epidural fentanyl speeds the onset of sensory block during epidural lignocaine anaesthesia. Regional Anaesthesia and pain medicine 2011;26(6):523-6.

10. Al-Ghanem SM, Massad IM, Al-Mustafa MM, et al. Effect of adding dexmedetomidine versus fentanyl to intrathecal bupivacaine on spinal block characteristics in gynaecological procedures: a double blind controlled study. American Journal of Applied Sciences 2009;6(5):882-7.

11. Harsoor SS, Sudheesh K. Dexmedetomidine in anaesthesia practice: a wonder drug? Indian J Anaesth 2011;55(4):323-4.

12. Arakawa M, Hoka S. Consideration of optimal epidural fentanyl doses in abdominal surgery. J Clin Anaesth 1998;10(7):551-6.

13. Singh BSJ, Sukhwinder KB, Kaur J, et al. Dexmedetomidine and clonidine in epidural anaesthesia: a comparative evaluation. Indian journal of Anaesthesia 2011;55(2):116-21.

14. Bajwa S, Arora V, Kaur J, et al. Comparative evaluation of dexmedetomidine and fentanyl for epidural analgesia in lower limb orthopaedic surgeries. Saudi Journal of Anaesthesia 2011;5(4):365-70.

15. Maroof M. Evaluation of effect of dexmedetomidine in reducing shivering following epidural anaesthesia. ASA annual meeting, abstract A-49. 